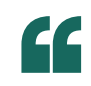

The cation

ordering

itself is highly

surprising as

ordering of

two $3^{+}$cations

at perovskite

$B$-sites is

unprecedented

$\Rightarrow$

DOUBLE PEROVSKITES

\title{
Equally charged with orderly conduct
}

Double perovskite oxides are valued for their versatile cation arrangements, which impart notable physical properties such as ferrimagnetism and large magnetoresistance. $\mathrm{B}^{\prime}$ and $\mathrm{B}^{\prime \prime}$ cation arrangements in such $\mathrm{A}_{2} \mathrm{~B}^{\prime} \mathrm{B}^{\prime \prime} \mathrm{O}_{6}$ materials span from entirely disordered to impeccably ordered. Cation ordering usually occurs when the oxidation states and radii of the ions are substantially different. A difference in oxidation state of two or more is generally required to achieve $\mathrm{B}^{\prime} / \mathrm{B}^{\prime \prime}$ cationordered double perovskites. There are approximately 650 known ordered double perovskites, but all cases to date featuring isovalent cations $\left(\mathrm{A}^{3+}{ }_{2} \mathrm{~B}^{\prime 3+} \mathrm{B}^{\prime \prime 3+} \mathrm{O}_{6}\right)$ are disordered. Now, writing in Angewandte Chemie, Athinarayanan Sundaresan and co-workers describe unusual ordering of $\mathrm{Fe}^{3+}$ and $\mathrm{Al}^{3+}$ in the double perovskite $\mathrm{Bi}_{2} \mathrm{FeAlO}_{6}$.

The bismuth-based perovskite oxide $\mathrm{BiAlO}_{3}$ is ferroelectric at room temperature, whereas its iron counterpart $-\mathrm{BiFeO}_{3}-$ is multiferroic with weakly coupled magnetism and ferroelectricity. A polar phase in which half of the $\mathrm{B}$ sites in $\mathrm{BiFeO}_{3}$ are replaced with non-magnetic $\mathrm{Al}^{3+}$ ions may exhibit a spontaneous magnetization that in turn may enhance magnetoelectric

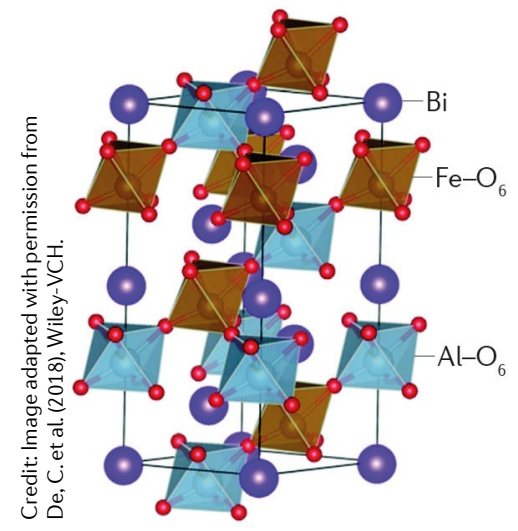

coupling. Since both $\mathrm{BiAlO}_{3}$ and $\mathrm{BiFeO}_{3}$ have similar crystalline phases, it is reasonable to expect that a $\mathrm{BiFe}_{1-x} \mathrm{AlO}_{3}$ solid solution is accessible. However, previous exploration of this composition space showed that the $\mathrm{BiFe}_{1-x} \mathrm{AlO}_{3}$ solid solution was limited to $x=0.1$ in bulk and $x=0.4$ in thin film. Attempts to stabilize a $\mathrm{BiFe}_{0.5} \mathrm{Al}_{0.5} \mathrm{O}_{3}$ phase at ambient pressure were unsuccessful.

A previous similar experience with the polar oxide $\mathrm{AlFeO}_{3}$ inspired the group to persevere. $\mathrm{Al}_{2} \mathrm{O}_{3}$ and $\mathrm{Fe}_{2} \mathrm{O}_{3}$ also have similar crystalline phases, but again an isostructural solid solution could not be formed. Instead, a 1:1 mixture unexpectedly crystallizes as $\mathrm{AlFeO}_{3}$ in a different space group. The isovalent cations in $\mathrm{AlFeO}_{3}$ are largely ordered, albeit with some partial anti-site disorder in which $\mathrm{Al}^{3+}$ and $\mathrm{Fe}^{3+}$ exchange sites. Although unprecedented, a 1:1 mixture of $\mathrm{BiAlO}_{3}$ and $\mathrm{BiFeO}_{3}$ may also yield ordered $\mathrm{Al}^{3+}$ and $\mathrm{Fe}^{3+}$ ions in a polar structure. Polar materials, or those with permanent dipoles, are required for ferroelectricity and other interesting behaviours.

Considering that high pressure stabilizes $\mathrm{BiAlO}_{3}$ as well as perovskite oxides with ordering of multiple cations (for example, double double perovskites), the group turned to a technique described earlier by collaborator and co-author Attfield. Polycrystalline samples of $\mathrm{BiFe}_{1-x} \mathrm{Al}_{x} \mathrm{O}_{3}$ with $x=0.2-0.5$ were prepared by pressing metal oxides at $6 \mathrm{GPa}(\sim 59,200 \mathrm{~atm})$ and $1,000^{\circ} \mathrm{C}$. Rietveld refinement of the expected polar rhombohedral $R 3 c$ model, with disordered $\mathrm{Fe}^{3+}$ and $\mathrm{Al}^{3+}$ ions, fitted $\mathrm{X}$-ray powder diffraction data for several $\mathrm{Fe}^{3+}: \mathrm{Al}^{3+}$ ratios, but not for $\mathrm{BiFe}_{0.5} \mathrm{Al}_{0.5} \mathrm{O}_{3}$. Instead, rock salt ordering of the $\mathrm{Fe}^{3+}$ and $\mathrm{Al}^{3+}$ cations on $\mathrm{B}^{\prime} / \mathrm{B}^{\prime \prime}$ sites occurs in the $\mathrm{BiFe}_{0.5} \mathrm{Al}_{0.5} \mathrm{O}_{3}$, or $\mathrm{Bi}_{2} \mathrm{FeAlO}_{6}$ double perovskite, in the $R 3$ space group, which is supported by time-of-flight neutron powder diffraction.

By replacing half of the $\mathrm{Fe}^{3+}$ ions in $\mathrm{BiFeO}_{3}$ with non-magnetic $\mathrm{Al}^{3+}$, the magnetic transition temperature from paramagnetic to an antiferromagnetic phase is decreased from $640 \mathrm{~K}$ to $280 \mathrm{~K}$. The dielectric constant exhibits conventional temperature dependence with a magnitude similar to that of $\mathrm{BiFeO}_{3}$, and lower conductivity that is dominated by a $d$-electron hopping mechanism. Piezoelectric measurements confirm that $\mathrm{Bi}_{2} \mathrm{FeAlO}_{6}$ exhibits a polar structure and ferroelectric properties at room temperature. The size difference between the $\mathrm{Al}^{3+}$ and $\mathrm{Fe}^{3+}$ cations as well as the nature of $\mathrm{Al}-\mathrm{O}$ and $\mathrm{Fe}-\mathrm{O}$ bonding may partly account for the cation ordering. However, there must be another factor at play because cation ordering is not observed in another similar compound, $\mathrm{LaAl}_{0.5} \mathrm{Fe}_{0.5} \mathrm{O}_{3}$. Distortions around the $\mathrm{Bi}^{3+}$ cations may accommodate the difference in isovalent cation radii, facilitating order. Although it is not well understood, the electron lone pair on $\mathrm{Bi}^{3+}$ might be key in achieving ordering. "The cation ordering itself is highly surprising as ordering of two $3^{+}$cations at perovskite B-sites is unprecedented," explains Sundaresan. "With appropriate selection of B'/B" cations, many polar materials of the type $\mathrm{Bi}_{2} \mathrm{~B}^{\prime} \mathrm{B}^{\prime \prime} \mathrm{O}_{6}$ may be accessible by the same high pressure methods."

Jacilynn Brant, Associate Editor, Nature Communications

ORIGINAL ARTICLE De, C. et al. Isovalent cation ordering in the polar rhombohedral perovskite $\mathrm{Bi}_{2} \mathrm{FeAlO}_{6}$. Angew. Chem. Int. Ed. https://doi.org/ 10.1002/anie.201810122 (2018) FURTHER READING De, C. et al. Nonswitchable polarization and magnetoelectric coupling in the high-pressure synthesized doubly ordered perovskites $\mathrm{NaYMnWO}_{6}$ and $\mathrm{NaHoCoWO}_{6}$. Phys. Rev. B 97, 214418 (2018) 